\title{
Excessive fasting times: still an underaddressed challenge for African pediatrics and anesthesia?
}

This article was published in the following Dove Press journal:

Pediatric Health, Medicine and Therapeutics

I I April 2014

Number of times this article has been viewed

\author{
Gregor Pollach ${ }^{1,2}$ \\ Rose Kapenda ${ }^{2}$ \\ Beauty Anusa ${ }^{2}$ \\ Ethel Waluza ${ }^{2}$ \\ Felix Namboya ${ }^{1,2}$ \\ 'Department of Anaesthesia and \\ Intensive Care, College of Medicine, \\ University of Malawi, ${ }^{2}$ Queen \\ Elizabeth Central Hospital, Blantyre, \\ Malawi, Central Africa
}

Correspondence: Gregor Pollach Department of Anaesthesia and Intensive Care, College of Medicine, University of Malawi, Mahatma Gandhi Avenue 6, PO Box 360, Blantyre 3, Chichiri, Blantyre, Malawi, Central Africa

Tel +2650999289570

Email gipi.bc62@yahoo.de
Background: Children are starved before surgery following international preoperative guidelines. Extreme fasting is still reported, but data for Africa are scarce. Starving in hot climates leads to challenges arising from dehydration, hypotension, metabolic disturbances, and complications during induction of anesthesia. The purpose of this study was to evaluate the scope of the problem, identify possible reasons for this, and propose realistic solutions.

Methods: We performed eleven prospective audits between 2008 and 2013 in Malawi to improve our preoperative fasting times. In total, 631 children (aged 3 days to 13 years) were monitored. Training was provided, and the results were measured using a visual analog scale.

Results: In 2008, the baseline audit showed a mean fasting time (MFT) of 13.48 hours ( 31 patients). Training reduced the MFT to 8.77 hours ( 73 patients) and 3.2 hours ( 35 patients) in 2009. Without training, the MFT increased to 4.6 hours (35 patients) in 2010 and to 10.2 hours (50 patients) in 2011. A low level of training decreased the MFT to 8.13 hours (139 patients, in spring 2012). Educational activity brought the MFT down further to 7.86 hours (36 patients, in summer 2012). Lack of training in autumn 2012 increased MFT to 9.32 hours (151 patients), which then improved to 8.04 hours ( 27 patients) as a result of renewed educational activity. In 2013, MFT increased to 9.8 hours (37 patients) despite training. In June 2013, more education achieved a reduction in MFT to 6.52 hours (17 patients). The MFT across all audits (2008-2013) was 8.48 hours. Education reduces MFT, but only in the short term. Factors responsible for changes in MFT were identified.

Conclusion: Excessive preoperative fasting is an underaddressed problem in Africa. Reduction is difficult, so it has to be accepted as an ongoing task.

Keywords: child, infant, fluid, education, developing countries, Africa, fasting

\section{Introduction}

Pediatric patients undergoing surgery should be starved in accordance with international preoperative fasting guidelines. This usually implies (including in our department) the $6 / 4 / 2$ rule for solid food, breast milk, and clear fluids. ${ }^{1,2}$ Nevertheless, prolonged periods of preoperative fasting are still reported. ${ }^{3-6}$ Data for resource-poor African countries are scarce, ${ }^{7,8}$ and long-term audits are lacking. At Queen Elizabeth Central Hospital, which is the largest hospital in Malawi, we identified that preoperative starving times were longer than the standards set by the anesthetic department. We audited the fasting duration in our patients on eleven occasions between 2008 and 2013 by brief interviews and provided nurses and guardians with training to improve the situation.

In addition to being stressful for both children and their caregivers, ${ }^{4}$ prolonged fasting times have several negative implications and contribute to poor anesthetic 
outcomes in Africa. ${ }^{9-11}$ Because of the high fluid turnover in children, fasting leads rapidly to dehydration and perioperative hypotension. Metabolic disturbances, electrolyte imbalances, and hypoglycemia are further complications to consider. Induction of anesthesia becomes complicated because of difficult intravenous access, the need for gas induction, and increased production of gastric acid, ${ }^{12}$ and fluid loss and cardiovascular instability are worsened by the hot atmosphere in a tropical hospital. ${ }^{9,13}$

In our setting, fasting means that important drugs (antibiotics, antimalarials, antiretrovirals) cannot be administered. Moreover, there is no evidence for a smaller gastric volume ${ }^{14,15}$ as a result of longer fasting. Specific groups of patients in the tropics are less able to cope with dehydration. Malnourished children, children with mechanical feeding challenges (noma, Hirschsprung's disease, omphalocele), mitral stenosis, or diabetes are especially vulnerable.

Further, in Africa, a caregiver with poor education, who cannot bear the hunger of her child any longer, might feed the child "Nsima" (balls of maize) shortly before surgery without informing the anesthetist.

\section{Materials and methods}

Between 2008 and 2013 we undertook eleven prospective clinical audits in order to monitor the preoperative fasting situation for pediatric anesthesia in our hospital. Between audits, we tried to provide training and education regarding fasting times for our nurses and caregivers. We measured fasting times for patients (aged from 3 days to 13 years) and calculated a mean fasting time (MFT), ie, the duration for which the patients had nil by mouth before surgery, ie, were fasted for fluids (and for breast milk and solids). Patients were admitted consecutively for each audit. Due to the complex way in which patients are admitted to the ward or treated as day cases, it was not possible to prospectively divide the patients into groups on this basis. We calculated the MFT in each audit. In total, 631 patients and caregivers were questioned carefully regarding the last time the child ate or drank.

Questioning was done via our Malawian collaborators, ie, anesthetic clinical officers, in the main local language (Chichewa). In-depth questioning of many of our caregivers regarding fasting times was surprisingly time-consuming and difficult, as has been previously reported in Europe. ${ }^{16}$ The MFT of each audit was then compared with the MFT of the previous audit, and the result was related to whether there was training available after the previous audit. Because this was a service evaluation including several audits, we did not need to seek ethical approval, in accordance with the National Health Service National Patient Safety Agency guidelines. ${ }^{17}$

Following the international guidelines, children who ate within 6 hours, drank breast milk within 4 hours, or drank clear fluid within 2 hours of surgery were postponed and not included in the audits.

In between audits we provided training for nurses, mothers, and caregivers via lectures, T-shirts for children with a sign "give me water at 6 am" (assuming that surgery would start at $8 \mathrm{am}$ ), talks, personal reminders, blackboards, preoperative visits, or posters. The intensity of training was measured using a visual analog scale scored from 1 to 10 . A score of 10 was defined as the maximal possible involvement in training on the part of our anesthetic clinical officers, whereby they would undertake this training without being responsible for service provision in theater or the intensive care unit.

\section{Results}

The overall MFT from 2008 to 2013 in our clinical audit of 631 children was 8.5 hours. The results are summarized in Table 1. After initially identifying the problem in 2008, we audited 31 guardians and patients and found an MFT of 13.5 hours. After a short training period for the ward nurses through our anesthetic clinical officers, MFT decreased to 8.8 hours ( 73 patients). In 2009, following further educational activity, a dramatic reduction to 3.2 hours was achieved (35 patients). In 2010, without any further training, the MFT increased again, but it was felt that 4.6 hours ( 35 patients) reflected the effects of previous training. All hospital activities were hampered in 2011 because of political turmoil, and we were unable to continue with training at this time. The MFT increased again to 10.2 hours (50 patients). A low level of training during the spring of 2012 was enough to decrease MFT to 8.13 hours (139 patients) and with a lot of effort (because the department lost 16 staff members for several months during a general financial crisis) to 7.9 hours (36 patients) in the summer of 2012. In October/November 2012, all training activity had to be diverted to another field, and MFT increased immediately to 9.32 hours (151 patients). In November/December 2012, our educational activity was increased as a result of external funding and MFT decreased to 8 hours (27 patients). Our most intensive training was commenced in 2013, and we found for the first time an increased MFT of 9.8 hours (37 patients) after training. Seeing the need for action, we further intensified our training, and in an ongoing audit have achieved a reduction in MFT to 6.51 hours (17 patients). 
Table I Overview of patient numbers, training, mean fasting time, training intensity, and changes in mean fasting time

\begin{tabular}{|c|c|c|c|c|c|c|c|c|}
\hline Audit & Date & $\begin{array}{l}\text { Patients } \\
\text { audited (n) }\end{array}$ & $\begin{array}{l}\text { Training } \\
\text { before audit? }\end{array}$ & $\begin{array}{l}\text { MFT } \\
\text { (hours) }\end{array}$ & $\begin{array}{l}\text { Training } \\
\text { after audit? }\end{array}$ & $\begin{array}{l}\text { MFT next } \\
\text { audit }(\uparrow / \downarrow)\end{array}$ & $\begin{array}{l}\text { Training } \\
\text { intensity (VAS) }\end{array}$ & Remarks \\
\hline I & $2008(1)$ & 31 & No & 13.48 & Yes & $\downarrow \downarrow$ & 5 & Baseline \\
\hline 2 & $2008(2)$ & 73 & Yes & 8.77 & Yes & $\downarrow \downarrow$ & 4.5 & \\
\hline 3 & 2009 & 35 & Yes & 3.2 & No & $\uparrow$ & 4.5 & \\
\hline 4 & 2010 & 35 & No & 4.6 & No & $\uparrow \uparrow$ & 0 & \\
\hline 5 & 2011 & 50 & No & 10.2 & Yes & $\downarrow$ & 0 & Political turmoil \\
\hline 6 & February to May, 2012 & 139 & Yes & 8.13 & Yes & $\downarrow$ & 2 & \\
\hline 7 & August to October, 2012 & 36 & Yes & 7.86 & No & $\uparrow$ & 4.5 & Staff of 16 \\
\hline \multirow[t]{2}{*}{8} & October to & $|5|$ & No & 9.32 & Yes & $\downarrow$ & 0 & \\
\hline & November, 2012 & & & & & & & \\
\hline \multirow[t]{2}{*}{9} & November to & 27 & Yes & 8.04 & Yes & $\uparrow$ & 5.5 & External funding \\
\hline & December, 2012 & & & & & & & \\
\hline 10 & January to February, 2013 & 37 & Yes & 9.8 & Yes & $\downarrow$ & 6.5 & 0 nurses \\
\hline II & May to June, 2013 & 17 & Yes & 6.51 & Yes & Following & 8 & Surgical involvement \\
\hline$\Sigma$ & $2008-2013$ & 631 & $7 \mathrm{Y} / 4 \mathrm{~N}$ & 8.48 & $8 \mathrm{Y} / 3 \mathrm{~N}$ & $\mathrm{~N} / \mathrm{A}$ & 3.7 & N/A \\
\hline
\end{tabular}

Abbreviations: MFT, mean fasting time; VAS, visual analog scale (I-I0); Y, yes; N, no; N/A, not applicable.

We showed that the MFT decreased after all phases of educational activity and training until 2013. In 2013, when more caregivers than nurses were in training, we saw for a short time the contrary (Figures 1 and 2). Education only worked in the short term, despite incorporation of highly qualified nurses on the surgical wards. The short-lived effects of education might not be considered uncommon, but we identified several detrimental factors which might not be well known in better resourced communities. These include lack of financial resources due to political turmoil, leading to unpaid staff, lack of drugs, and lack of basic equipment (eg, chalk for the blackboard) at the regional level; frequent staff rotation and communication breakdown at the hospital level; and lack of general education and inability to understand physiological interactions, combined with lack of social support during the hospital stay, at the caregiver level. The quality of training under these conditions was influenced by challenges to do with ownership, empowerment, and hierarchy, and also by clinical demands with regard to training time and the duties our staff have to their own extended families in the African context.

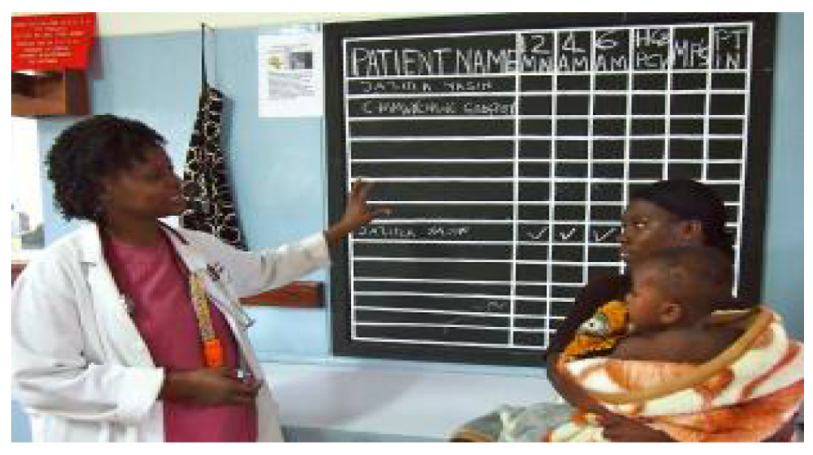

Figure I Training of a caregiver by an anesthetic clinical officer.
We had to conclude that in spite of the various types of educational activities we used for mothers, caregivers, nurses, and nurses in charge of wards, we were not able to identify a single method which proved to be more sustainable than the others.

A specific subgroup of children could be identified for whom the caregivers may need a totally different educational approach. These children were usually accompanied by an older caregiver, eg, a grandmother or a guardian with a limited knowledge of Chichewa (such as patients from the north of the country or from Mozambique). These are the children who had extremely long fasting times (up to 32 hours) despite training in almost all audits over the years.

Although we were not able to lower MFT to a level compatible with anesthetic guidelines, a reduction was achieved, and it was possible to keep the MFT at a relatively stable level. We found very few children who could not undergo surgery because they ate or drank too close to their procedure. Surgery had to be deferred in these children, so they were excluded from the audits. Our auditors estimated that these children numbered less than 5\%. A clinical audit of fasting times over several years is a challenging task in Africa, but is possible and would be useful for improving service provision in a government hospital (Table 1).

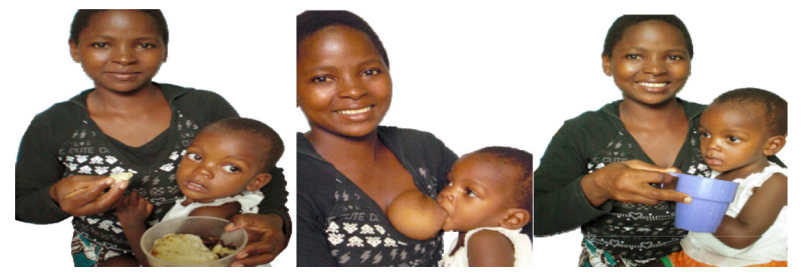

Figure 2 Caregiver and child posing for the poster: "When to give food, breast milk and water." 


\section{Discussion}

To the best of our knowledge, this is the first report of excessively long fasting times in a hospital in Central Africa since the introduction of international guidelines. ${ }^{1,2}$ Published reviews addressing challenges in pediatric anesthesia in Africa do not mention long fasting times as a problem..$^{9,10}$

The MFT at Queen Elizabeth Central Hospital was too long in each of the clinical audits conducted over the last 5 years. Reasons mentioned for long fasting times in the developed world - nurses still order "nil by mouth after midnight", that they dealt with an outpatient population ${ }^{3}$ or that obviously wrong information was given to secure timely flexibility for the theatre ${ }^{18}$ were not typical for our hospital.

Children being starved of water for a mean of 8.5 hours, as at our institution, exceeds the recommendations of all international guidelines. The Queen Elizabeth Central Hospital is by far the largest teaching hospital in Malawi for masters in medicine, doctors, anesthetic clinical officers, clinical officers, and all cadres of nurses, from whom education and information spreads throughout the country; because we have structural challenges similar to those of other large African countries, it is suspected that prolonged fasting times are a problem throughout Malawi and probably in other resourcepoor African countries as well.

Considering the consequences for induction of anesthesia (dehydration, hypotension, difficult intravenous access, gas induction, metabolic disturbances, insulin resistance, and hypermetabolism ${ }^{19}$ ) and the interruption of antibacterial, antiviral or antiparasitic treatment, excessive fasting times might be an overlooked challenge, responsible for poor anesthetic outcomes in African countries. ${ }^{20-22}$

Education for mothers, caregivers, and nurses was nearly always able to lower the MFT. Different methods were used during the 5-year study. Whether we used lectures, personal talks, posters, printed T-shirts, discussion groups, or questionnaires to reinforce our message seemed not to be important, in that the MFT still decreased. The only exception was audit 10, when MFT was prolonged in spite of intense training. For the first time, we focused on caregivers, because of findings regarding their effectiveness in situations of food crisis in Africa, ${ }^{23}$ and our Malawian trainers had to adjust their level of communication to this less educated group, which might explain this difficulty, especially given that an ongoing clinical audit, after further adjustment, seems to indicate a decrease in MFT.

Nevertheless, we were still not able to reduce MFT to within acceptable time limits. Obviously we should intensify our education for health care professionals and caregivers. Behavioral changes concerning fasting times already pose a challenge in the developed world, ${ }^{24}$ and easily overstretch our limited staff resources. It might seem easy to give the necessary information and training and to ask the question "when was the last time your child drank before the operation?", but this was not the case in our study. Our Malawian clinical anesthetic officers were surprised how difficult it was to make their message understood. For example, a mother might be attending to other siblings at the same time, a grandmother might not understand anything, an older sister might not have any knowledge about basic physiology, an aunt might not be willing to wake the child up in time, and the whole family might speak Sena instead of Chichewa because they originate from Mozambique.

Moreover, there may be a more fundamental reason for the long MFTs observed in this study, originating in the already long fasting hours during daily life in our population. It could be the mere fact that a long interval between meals is a normal part of village life because people cannot afford more than two meals a day. This fits well with our observation that few children were postponed because they ate or drank in the "forbidden" period of 2/4/6 hours. Given the consequences of excessive fasting, we see an argument to shift attention away from prevention of aspiration towards prevention of extreme fasting in elective cases.

Education only had an effect in the short term. MFT was prolonged after each period without training, probably as a result of constant staff rotation, high numbers of shifts with disinterested locum staff, and the generally stressful working environment of all health professionals. Constant supervision and education is necessary for improved services. In our ongoing audit, a combination of feedback via a blackboard in the ward for the caregiver (the mother has to tick when she gave something to the child) and involvement already taking place in the surgical clinic (talking about fasting, before the first anesthetist saw the child) is being attempted. However, the issue of whether national guidelines or local protocols are more suited to solve this problem ${ }^{25}$ is of no importance in our setting.

We have to conclude that some of the challenges in lowering MFT cannot be solved by us at all, given the extremely low education level of our patients, the dire financial situation of the country, which forces us to concentrate funding on pure service provision, and a structure of staff rotation which is a challenging part of the prevailing political system. None of these issues can be tackled without sincere commitment from government.

Several limitations are inherent in this clinical audit study, the most important of which are likely to be its relatively 
small numbers (which cannot exclude random fluctuation), the different teaching personnel over the years, and the lack of sample size standardization and statistical analysis. Being an audit designed to improve service provision rather than a research study, there was no randomization.

\section{Conclusion and recommendations}

Excessive fasting times may be an underaddressed problem in the African setting. Reduction of fasting times is possible (albeit difficult), and we have to accept that it is an ongoing task. Persistence with training and education for nurses and caregivers, better preoperative patient information (already in the surgical clinic), and securing of preoperative intravenous access the night before surgery are necessary to overcome the well-established, often multifactorial, and longstanding challenges associated with pediatric anesthesia.

\section{Acknowledgments}

The authors are grateful to Drs Downie, Amaia Arana Galdos, Peltola, and Wiesener, and to Mrs Priscilla Moyo, for their assistance with this research.

\section{Disclosure}

The authors report no conflicts of interest in this work. No specific funding was received for this research. All audits were done during working hours or night shifts without additional payment. The only additional money involved consisted of approximately US $\$ 200$ for a blackboard, some T-shirts arranged by the head of department (GP) and a local company producing T-shirts for the patients in the second audit in 2008. That company did not influence the audit in any way.

\section{References}

1. American Society of Anesthesiologists Committee on Standards and Practice Parameters. Practice guidelines for preoperative fasting and the use of pharmacologic agents to reduce the risk of pulmonary aspiration: application to healthy patients undergoing elective procedures. An updated report. Anesthesiology. 2011;114:495-511.

2. Smith I, Kranke P, Murat I, et al. Perioperative fasting in adults and children: guidelines from the European Society of Anaesthesiology. Eur J Anaesthesiol. 2011;28:556-569.

3. Arun BG, Korula G. Perioperative fasting in children: an audit and its implications in a tertiary care hospital. J Anaesthesiol Clin Pharmacol. 2013;29:88-91.

Pediatric Health, Medicine and Therapeutics

\section{Publish your work in this journal}

Pediatric Health, Medicine and Therapeutics is an international, peerreviewed, open access journal publishing original research, reports, editorials, reviews and commentaries. All aspects of health maintenance preventative measures and disease treatment interventions are addressed within the journal. Practitioners from all disciplines are invited to submit
4. Engelhardt T, Wilson G, Horne L, Weiss M, Schmitz A. Are you hungry? Are you thirsty? - fasting times in elective outpatient pediatric patients. Paediatr Anaesth. 2011;21:964-968.

5. Baril P, Portman H. Preoperative fasting: knowledge and perceptions. AORN J. 2007;86:609-617.

6. Miller DC. Why are children starved? Br J Anaesth. 1990;64: 409-410.

7. Foulkes-Crabbe DJ, Johnson TO. Effect of anaesthesia and surgery on blood sugar and carbohydrate tolerance in African children. Can Anaesth Soc J. 1976;23:486-491.

8. Adudu OP, Egwakhide EOA, Adudu OG. Parents and patients' compliance to revised preoperative fasting guidelines in Benin, Nigeria. Paediatr Anaesth. 2008;8:1013-1014.

9. Hodges SC, Walker IA, Bösenberg AT. Paediatric anaesthesia in developing countries. Anaesthesia. 2007;62:26-31.

10. Bösenberg AT. Pediatric anesthesia in developing countries. Curr Opin Anaesthesiol. 2007;20:204-210.

11. Ekenze SO, Ikechukwu RN, Oparaocha DC. Surgical correctable congenital anomalies: prospective analysis of management problems and outcome in a developing country. J Trop Pediatr. 2006;52:126-131.

12. Cote CJ, Goudsouzian NG, Liu L, Dedrick DF, Szyfelbein SK. Assessment of risk factors related to the acid aspiration syndrome in pediatric patients - gastric $\mathrm{pH}$ and residual volume. Anesthesiology. 1982;56:70-72.

13. Mock C, Visser L, Denno D, Maier R. Aggressive fluid resuscitation and broad spectrum antibiotics decrease mortality from typhoid ileal perforation. Trop Doct. 1995;3:115-117.

14. Crawford M, Lerman J, Christensen S, Farrow-Gillespie A. Effects of duration of fasting on gastric fluid $\mathrm{pH}$ and volume in healthy children. Anesth Analg. 1990;71:400-403.

15. Brady M, Kinn S, Ness V, O’Rourke K, Randhawa N, Stuart P. Preoperative fasting for preventing perioperative complications in children. Cochrane Database Syst Rev. 2009;4:CD005285.

16. Cantellow S, Lightfoot J, Bould H, Beringer R. Parent's understanding of and compliance with fasting instruction for pediatric day case surgery. Pediatr Anaesth. 2012;22:897-900.

17. National Research Ethics Service, National Patient Safety Agency: Defining Research, NHS, 2007, issue 3.

18. Murphy GS, Ault ML, Wong HY, Szokol JW. The effect of a new NPO policy on operating room utilization. J Clin Anesth. 2000;12:48-51.

19. Svanfeldt M, Thorell A, Brismar K, Nygren J, Ljungquist O. Effects of 3 days of "postoperative" low caloric feeding with or without bed rest on insulin sensitivity in healthy subjects. Clin Nutr. 2003;22:31-38.

20. Glenshaw M, Madzimbamuto FD. Anaesthesia associated mortality in a district hospital in Zimbabwe: 1994 to 2001. Cent Afr J Med. 2005;51:39-44.

21. Ouro-Bang'na Maman AF, Tomta K, Ahouangbévi S, Chobli M. Deaths associated with anaesthesia in Togo, West Africa. Trop Doct. 2005;35: $220-222$.

22. Hansen D, Gausi SC, Merikebu M. Anaesthesia in Malawi: complications and deaths. Trop Doc. 2000;30:146-149.

23. Kiros GE, Hogan DP. War, famine and excess child mortality in Africa: the role of parental education. Int J Epidemiol. 2001;30:447-456.

24. Crenshaw JT, Winslow EH. Preoperative fasting duration and medication instruction: are we improving? AORN J. 2008;88:963-976.

25. Saqr L, Chambers WA. Preventing excessive pre-operative fasting: national guidelines or local protocol? Anaesthesia. 2006;61:1-3.

\section{Dovepress}

their work as well as healthcare researchers and patient support groups. The manuscript management system is completely online and includes a very quick and fair peer-review system. Visit http://www.dovepress.com/ testimonials.php to read real quotes from published authors. 